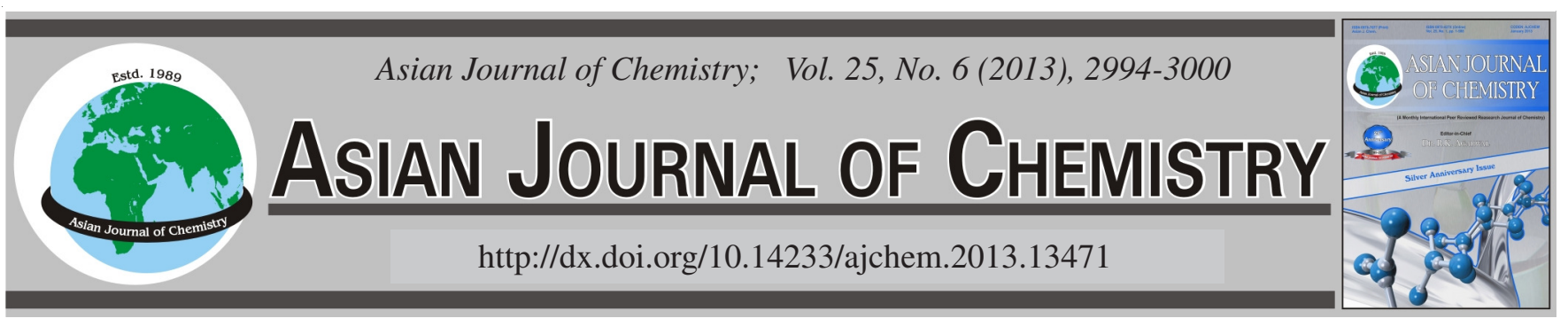

\title{
Effect of Different Extraction Media on Quantification of the Released Monomers from Dental Composite
}

\author{
Pinar Gul ${ }^{1, *}$, Fatma Demirkaya Miloglu ${ }^{2}$, Nilgun Akgul $^{1}$ and Yucel Kadioglu ${ }^{2}$
}

${ }^{1}$ Department of Restorative Dentistry, School of Dentistry, Atatürk University, Erzurum 25240, Turkey

${ }^{2}$ Department of Analytical Chemistry, School of Pharmacy, Atatürk University, Erzurum 25240, Turkey

*Corresponding author: Fax: +90 44223609 45; Tel: +90 44223138 82; E-mail: opinargul@ gmail.com

(Received: 19 January 2012;

Accepted: 5 December 2012)

AJC-12504

\begin{abstract}
Many factors affect the amount of released monomers from composite resins. The aim of this study is to measure the release of monomers from microhybrid composite resin Filtek Z250 (3 M ESPE, USA) for a long time [1 h, $24 \mathrm{~h}, 7 \mathrm{~d}(168 \mathrm{~h})$ and $30 \mathrm{~d}(720 \mathrm{~h})]$ after the polymerization and observe the effect of different extraction media [ethanol/water solutions $(75: 25$, v/v), distilled water, artificial saliva] on released monomers. Twelve specimen discs were prepared using composite resin for each analyte. Quantitative analysis of released monomers from composite resin was determined by using high performance liquid chromatography. Data were analyzed using one way ANOVA and Duncan test. All monomers were released in ethanol/water solution higher efficiency than the other media and the highest amount of release is obtained from BisGMA $(p<0.05)$. Maximum release of all monomers occurred within the first hour and after $24 \mathrm{~h}$, the amount of released monomer generally reduced by $30 \mathrm{~d}$.
\end{abstract}

Key Words: Artificial saliva, Dental composite, Distilled water, Ethanol/water solution, Residual monomer.

ᄂ - - - - - - - - - - - - - - - - - - - - - - - - - -

\section{INTRODUCTION}

The increased demand for esthetic dental restorations during the last few years in the general dental practice has caused an increase in use of composite materials ${ }^{1}$. Light-cured polydimethacrylate-based resins and resin composites are extensively used in dentistry in a variety of applications, for example, fissure sealants, bonding agents, resin cements and filling materials. They possess excellent mechanical properties, rapid polymerization, aesthetic quality, ease of handling and the ability to bond to enamel surface. However, concerning about their clinical reliability still remains ${ }^{2}$. Despite of being considered highly stable structures, dental composites are susceptible to degradation due to the incomplete polymerization and the influence of the aqueous oral environment ${ }^{3-5}$. A lot of studies indicated that various components may be released from composite restorations into the oral environment ${ }^{3}$. The liberation of components from composite resins may influence the biocompatibility of the restorations ${ }^{6}$. Substances eluted from the polymerized materials (residual monomers, impurities of monomers, additives, degradation products) may irritate the soft tissue, stimulate the growth of bacteria and promote allergic reactions $\mathrm{s}^{2,7}$.

The effects on the results of toxicity testing of dental composites vary with different immersion media ${ }^{8}$. These immersion media include culture medium, distilled water, artificial saliva and ethanol/water solution ${ }^{2,8,9-11}$. Ethanol/water solution $(75: 25, \mathrm{v} / \mathrm{v})$ is recommended by food and drug administration guidelines of USA as a food simulator and might be considered clinically relevant. It simulates certain beverages (including alcoholic), vegetables, fruits and syrup ${ }^{10}$.

The determination of the quality and quantity of the residual monomers eluted from dental resin materials is usually performed by using high performance liquid chromatography ${ }^{12-22}$. Other techniques also used gas-liquid chromatography $^{7}$, gas and liquid chromatography/mass spectrometry ${ }^{23-25}$ and very recently, the electrospray ionization/mass spectrometry $^{26}$ and the micellar electrokinetic chromatography ${ }^{2}$.

The aim of this study was to determine the amount of main residual monomers (BisGMA, TEGDMA and UDMA) released from microhybrid composite after different storage times, using HPLC method and evaluate the effect of different extraction media on released monomers.

\section{EXPERIMENTAL}

In this study, the commercial composite, Filtek Z250 (3 M ESPE, St. Paul, MN, USA) was used. Filtek Z250 is one of the radiopaque microhybrid composites. According to the brochure of manufacturer, resin matrix (23 wt \%) consists of BisGMA, UDMA, TEGDMA and BisEMA. The filler (77 wt \% 
or $60 \mathrm{vol} \%$ ) consist of zirconia/silica, with a particle size range of 0.01-3.5 $\mu \mathrm{m}$. Three different immersion media used in this study which were (1) distilled water (2) artificial saliva and (3) ethanol/water solutions (75:25, v/v). BisGMA, TEGDMA and UDMA were purchased from Sigma-Aldrich (Taufkirchen, Germany)

Preparation of specimens: Twelve specimen discs were prepared for each analyte in three media. Specimen discs were prepared in Teflon molds with a diameter of $5.0 \mathrm{~mm}$ and a thickness of $4.0 \mathrm{~mm}$. The mold positioned on a mylar strip on a glass slab and was filled with the unpolymerized material and then the filled mold was covered with a mylar strip and was pressed with a glass slab. Sample in the mold was light cured for $40 \mathrm{~s}$ from the top and the bottom of surfaces with a light-curing device (Elipar Freelight II, 3M-ESPE, Seefeld, Germany). The mean output intensity of the light source was $1200 \mathrm{~mW} / \mathrm{cm}^{2}$, as assessed by the radiometer (Hilux Ultra Plus Curing Units, Benlioglu Dental). The distance between the light source and specimen was standardized by using a $1 \mathrm{~mm}$ glass plate. After curing, specimens were weighed (Sartorius AG Gottingen-3105, Germany, readability $\pm 0.01 \mathrm{mg}$ ) and then immediately each specimens was placed in a glass vial containing $0.5 \mathrm{~mL}$ of ethanol/water solution and twelve vials were prepared for analysis of three different analytes. While composite resins in solutions became stable in vials, solutions renewed four times after $1 \mathrm{~h}, 24 \mathrm{~h}, 168 \mathrm{~h}(7 \mathrm{~d})$ and $720 \mathrm{~h} \mathrm{(30}$ d). We analyzed all of the obtained solutions that are prepared in every hour mentioned below with developed methods for BisGMA, TEGDMA and UDMA. We have done exactly same procedure for vials that containing $0.5 \mathrm{~mL}$ artificial saliva and distilled water. All of samples were kept at $37^{\circ} \mathrm{C}$ and each analysis repeated four times. Quantitative analysis of BisGMA, TEGDMA and UDMA released from microhybrid composite resin was determined by using HPLC.

Equipment and chromatographic conditions: Analyses of BisGMA, TEGDMA and UDMA were achieved by using the HPLC system (Thermoquest spectra system P 1500) consisting of a pump, a column oven, an autosampler and a photodiode array detector (DAD) coupled with a $\mathrm{C}_{18}$ analytical column $(250 \times 4.6 \mathrm{~mm}, 5 \mu \mathrm{m})$ (Phenomenex Jupiter, USA). While the isocratic elution with a mobile phase consisting of methanol (Merck (Germany)) and water (80:20, v/v) was used for a BisGMA analysis, TEGDMA and UDMA analysis was performed by isocratic elution with a mobile phase consisting of acetonitrile (Merck (Germany)) and water [(62:38, v/v) for TEGDMA and $(75: 25, \mathrm{v} / \mathrm{v})$ for UDMA]. The flow rate of all three HPLC methods was $1 \mathrm{~mL} / \mathrm{min}$. BisGMA, TEGDMA and UDMA were monitored at $225 \mathrm{~nm}, 203 \mathrm{~nm}$ and $210 \mathrm{~nm}$, respectively.

Treatment of ethanol/water solution, distilled water and artificial saliva samples: For analysis of BisGMA, 0.5 $\mathrm{mL}$ of samples were taken from all three media and $10 \mu \mathrm{L}$ of methanol was added to each of them. Each sample was mixed and evaporated to dryness at $100{ }^{\circ} \mathrm{C}$ under a nitrogen stream. The residue was dissolved methanol and was injected into the chromatographic system. For analysis of TEGDMA and UDMA, $0.5 \mathrm{~mL}$ samples were taken from all three media and $10 \mu \mathrm{L}$ of methanol was added to each of them. Each sample was mixed and injected into the chromatographic system.
Statistical analysis: One-way ANOVA followed by Duncan post hoc tests was used to compare the amount of released monomers in terms of time intervals and extraction media. (Significance levels 0.05).

\section{RESULTS AND DISCUSSION}

In the present study, the amounts of eluted monomers from the dental composite in three immersion media at different time intervals using HPLC was investigated. HPLC analysis is one of the most confidence and commonly used quantification method among other techniques ${ }^{8}$. Specimens in the present study were fabricated in the same experimental condition (specimen size, curing time and intensity, immersion time and media).

Development and validation HPLC method for BisGMA, TEGDMA and UDMA application: For standard BisGMA, TEGDMA and UDMA, obtained chromatograms are exhibited in Figs. 1A, 2A and 3A for ethanol/water, distilled water artificial saliva media, respectively. After keeping in ethanol/water solution, distilled water and artificial saliva for $1 \mathrm{~h}, 24 \mathrm{~h}, 7 \mathrm{~d}$ and $30 \mathrm{~d}$, we analyzed BisGMA, TEGDMA and UDMA samples that are obtained from dental composite resin. All chromatograms that are taken from this procedure are showed in Figs. 1B, 2B and 3B (ethanol/water), Figs. 1C, $2 \mathrm{C}$ and $3 \mathrm{C}$ (distilled water) and Figs. 1D, 2D and 3D (artificial saliva). Elution times of BisGMA, TEGDMA and UDMA were $6.9 \pm 0.1,5.8 \pm 0.1$ and $5.5 \pm 0.1 \mathrm{~min}$, respectively. The abovementioned chromatograms demonstrated the excellent selectivity and sensitivity of the methods developed for all of the three analytes and three media. The regression equations were obtained by the least-square regression method in order to determine the linearity of methods. In a range of 0.2-100 $\mathrm{mg} / \mathrm{mL}$ for all three analytes and three media, method showed a good linearity. Relative standard deviation value gives the precision of the HPLC systems and relative error value gives the accuracy of the HPLC systems. The LOD, defined as the lowest concentration of analyte that can be detected and LOQ, defined as the lowest concentration of analyte that can be quantified, were estimated from the low concentration standards of analytes (BisGMA, TEGDMA and UDMA) in sample matrixes (ethanol/water, distilled water, artificial saliva). The obtained analytical data are summarized in Table- 1 .

After finishing validation part, the proposed methods were applied to the determination of BisGMA, TEGDMA and UDMA in each samples treated according to the procedure described above about dental composite resin in three media. (Figs. 1B-D, 2B-D and 3B-D).

Release of dental monomers: The amounts of eluted monomers from the dental composite in three immersion media at four different time are shown in Table-1. Statistically significant differences were determined with changing time intervals and media in terms of monomer release $(\mathrm{p}<0.05)$. All monomers were released in ethanol/water solution higher amount than the other media but BisGMA was released as maximum $(\mathrm{p}<0.001)$. In addition, UDMA was released more than other monomers in artificial saliva $(\mathrm{p}<0.01)$. TEGDMA in distilled water and artificial saliva were higher than that of BisGMA whereas the case was reverse in ethanol/water solution. Observing amount of monomer depending on time, maximum release of all monomers occured within the first 
hour $(\mathrm{p}<0.05)$. After $24 \mathrm{~h}$, the amount of released monomer reduced generally either gradually as one month or any statistically difference was observed between $7 \mathrm{~d}$ and $30 \mathrm{~d}$ released monomers by depending on the effect of media.
Ortengren et $a l .{ }^{20}$ investigated the elution of monomers from resin-based materials with storage times ranging from $4 \mathrm{~h}$ to $180 \mathrm{~d}$, observing a maximum monomer concentration after 7 days. Sideridou and Achilias ${ }^{2}$ measured the amount of

TABLE-1

ANALYTICAL PARAMETERS OF HPLC METHODS FOR BiSGMA, TEGDMA AND UDMA AND ANALYSIS RESULTS OF BisGMA, TEGDMA AND UDMA RECEIVED FROM DENTAL COMPOSITE RESIN (FILTEK Z250) JUST AFTER THEY WERE KEPT IN ETHANOL/WATER SOLUTION (75:25, v/v), DISTILLED WATER AND ARTIFICIAL SALIVA WAS FOR $1 \mathrm{~h}, 24 \mathrm{~h}, 7 \mathrm{~d}$ AND $30 \mathrm{~d}$

\begin{tabular}{|c|c|c|c|c|c|c|c|c|c|c|}
\hline \multirow[b]{2}{*}{$\begin{array}{l}\text { Parameters and } \\
\text { dental } \\
\text { composite resin }\end{array}$} & \multirow[b]{2}{*}{ Times } & \multicolumn{3}{|c|}{ BisGMA $(\mathrm{X} \pm \mathrm{SD})$} & \multicolumn{3}{|c|}{ TEGDMA $(\mathrm{X} \pm \mathrm{SD})$} & \multicolumn{3}{|c|}{ UDMA $(\mathrm{X} \pm \mathrm{SD})$} \\
\hline & & $\begin{array}{l}\text { Ethanol/water } \\
(75: 25, \mathrm{v} / \mathrm{v})\end{array}$ & $\begin{array}{l}\text { Distilled } \\
\text { water }\end{array}$ & $\begin{array}{l}\text { Artificial } \\
\text { saliva }\end{array}$ & $\begin{array}{c}\text { Ethanol/ } \\
\text { water } \\
(75: 25, \mathrm{v} / \mathrm{v})\end{array}$ & $\begin{array}{l}\text { Distilled } \\
\text { water }\end{array}$ & $\begin{array}{l}\text { Artificial } \\
\text { saliva }\end{array}$ & $\begin{array}{c}\text { Ethanol/ } \\
\text { water } \\
(75: 25, \mathrm{v} / \mathrm{v})\end{array}$ & $\begin{array}{l}\text { Distilled } \\
\text { water }\end{array}$ & $\begin{array}{l}\text { Artificial } \\
\text { saliva }\end{array}$ \\
\hline Slope (a) & - & 201847 & 193351 & 190305 & 250881 & 204729 & 143285 & 185874 & 175243 & 171322 \\
\hline $\mathrm{Sa}$ & - & 39933.1 & 10556.9 & 6526.8 & 3029.9 & 8737.7 & 1046.9 & 2740.6 & 3343.7 & 5869.7 \\
\hline Intercept (b) & - & -108747 & -143647 & -170262 & 216180 & 348934 & 58470 & 198131 & 91000 & 39896 \\
\hline $\mathrm{Sb}$ & - & 4958.8 & 73498.6 & 56395.3 & 94789.7 & 57686.2 & 19115.4 & 35722.8 & 41839.5 & 77113.7 \\
\hline $\begin{array}{l}\text { Coefficient of } \\
\text { correlation }\left(\mathrm{R}^{2}\right)\end{array}$ & - & 0.9996 & 0.9992 & 0.9995 & 0.9994 & 0.9975 & 0.9993 & 0.9976 & 0.9991 & 0.9994 \\
\hline $\begin{array}{l}\text { Linearity range } \\
\qquad(\mu \mathrm{g} / \mathrm{mL})\end{array}$ & - & $0.2-100$ & $0.2-100$ & $0.2-100$ & $0.2-100$ & $0.2-100$ & $0.2-100$ & $0.2-100$ & $0.2-100$ & $0.2-100$ \\
\hline $\begin{array}{l}\text { Detection limit } \\
\qquad(\mu \mathrm{g} / \mathrm{mL})\end{array}$ & - & 0.01 & 0.06 & 0.08 & 0.01 & 0.02 & 0.05 & 0.01 & 0.02 & 0.05 \\
\hline $\begin{array}{l}\text { Accuracy range } \\
\text { (RE) }\end{array}$ & - & $-6.48-1.55$ & $-3.44-2.89$ & $-6.70-5.95$ & $-4.81-6.65$ & $4.75-9.59$ & $-7.21-7.95$ & $-2.69-8.64$ & $3.17-9.06$ & $-0.52-8.26$ \\
\hline $\begin{array}{l}\text { Precision range } \\
\text { (RSD \%) }\end{array}$ & - & $3.59-6.04$ & $0.71-4.92$ & $2.52-4.39$ & $1.92-10.76$ & $3.03-4.67$ & $0.89-2.59$ & $1.35-4.29$ & $3.58-7.39$ & $1.08-9.75$ \\
\hline & $1 \mathrm{~h}$ & $13.79(1.69)^{\mathrm{b}}$ & $0.32(0.03)^{\mathrm{b}}$ & $0.34(0.05)^{\mathrm{c}}$ & $1.27(0.12)^{b}$ & $0.92(0.09)^{\mathrm{d}}$ & $0.52(0.19)^{b}$ & $4.87(1.54)^{\mathrm{c}}$ & $1.13(0.12)^{c}$ & $1.09(0.18)^{\mathrm{c}}$ \\
\hline Dental & $24 \mathrm{~h}$ & $13.31(1.72)^{\mathrm{b}}$ & $0.25(0.02)^{\mathrm{ab}}$ & $0.23(0.03)^{\mathrm{b}}$ & $0.77(0.04)^{\mathrm{a}}$ & $0.56(0.11)^{\mathrm{c}}$ & $0.43(0.03)^{b}$ & $2.26(0.10)^{\mathrm{b}}$ & $0.38(0.09)^{\mathrm{b}}$ & $0.51(0.03)^{b}$ \\
\hline composite resin & $7 \mathrm{~d}$ & $9.90(2.36)^{\mathrm{a}}$ & $0.19(0.08)^{\mathrm{a}}$ & $0.14(0.008)^{\mathrm{a}}$ & $0.85(0.02)^{\mathrm{a}}$ & $0.32(0.03)^{b}$ & $0.05(0.01)^{\mathrm{a}}$ & $1.19(0.24)^{\mathrm{ab}}$ & $0.16(0.007)^{\mathrm{a}}$ & $0.56(0.03)^{b}$ \\
\hline (Filtek Z250) & $\begin{array}{c}30 \mathrm{~d} \\
\mathrm{p}^{*}\end{array}$ & $\begin{array}{c}10.21(1.07)^{\mathrm{a}} \\
0.015^{*}\end{array}$ & $\begin{array}{c}0.16(0.08)^{\mathrm{a}} \\
0.018^{*}\end{array}$ & $\begin{array}{c}0.13(0.007)^{\mathrm{a}} \\
0.001 * *\end{array}$ & $\begin{array}{c}0.76(0.12)^{\mathrm{a}} \\
0.001 * *\end{array}$ & $\begin{array}{c}0.09(0.005)^{\mathrm{a}} \\
0.001 * *\end{array}$ & nd & $0.97(0.23)^{\mathrm{a}}$ & nd & $\begin{array}{c}0.03(0.03)^{\mathrm{a}} \\
0.001 * *\end{array}$ \\
\hline
\end{tabular}

$\mathrm{Sa}$; Standard deviation of slope of regression line; Sb; Standard deviation of intercept of regression line; X: concentration mean $(\mu \mathrm{g} / \mathrm{mL}), \mathrm{SD}$ : standard deviation, nd: under LOD values; *One-way ANOVA, ${ }^{*} \mathrm{p}<0.05, * * \mathrm{p}<0.001$; Within each column, means with the same superscript letters are not statistically different from each other
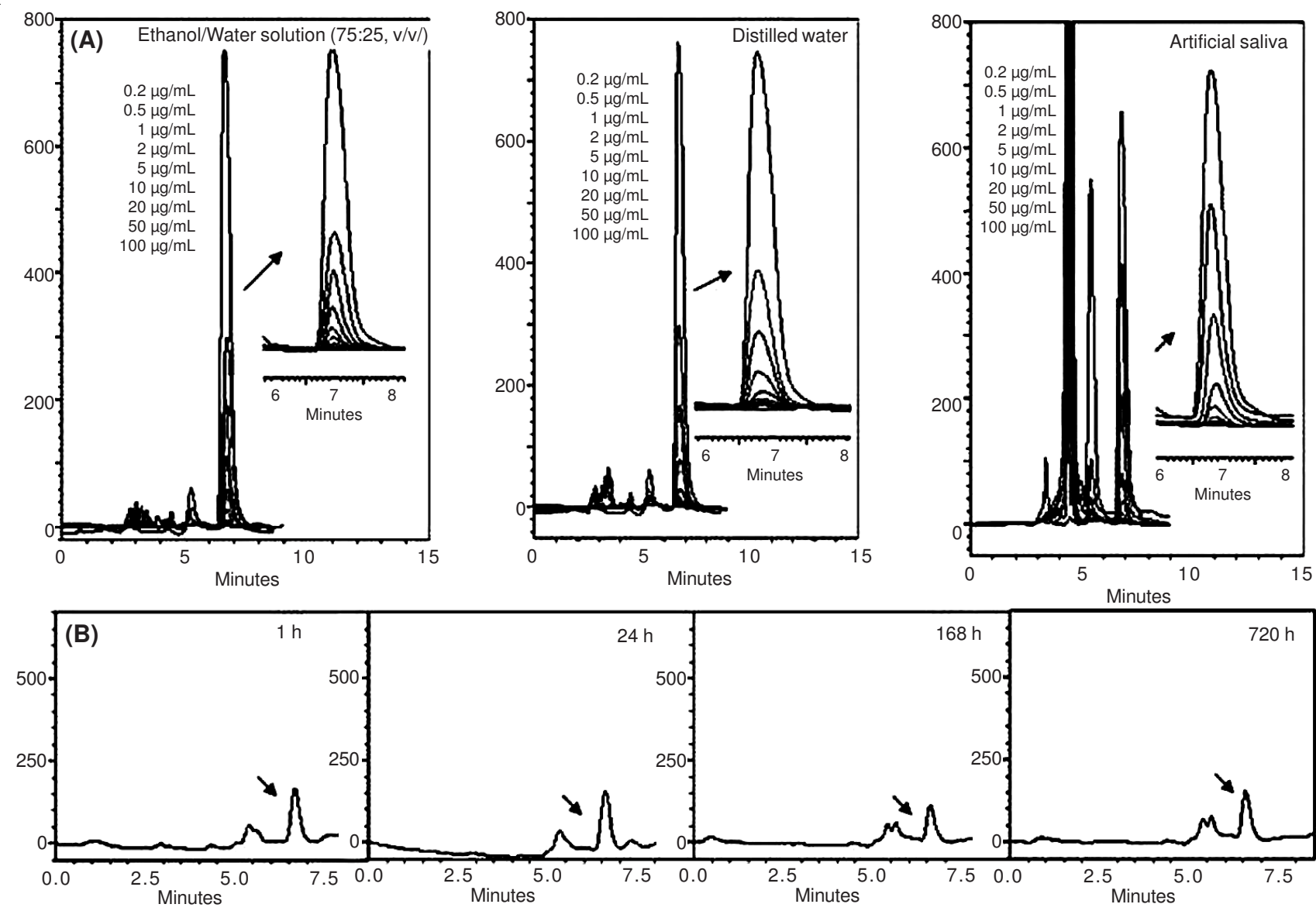

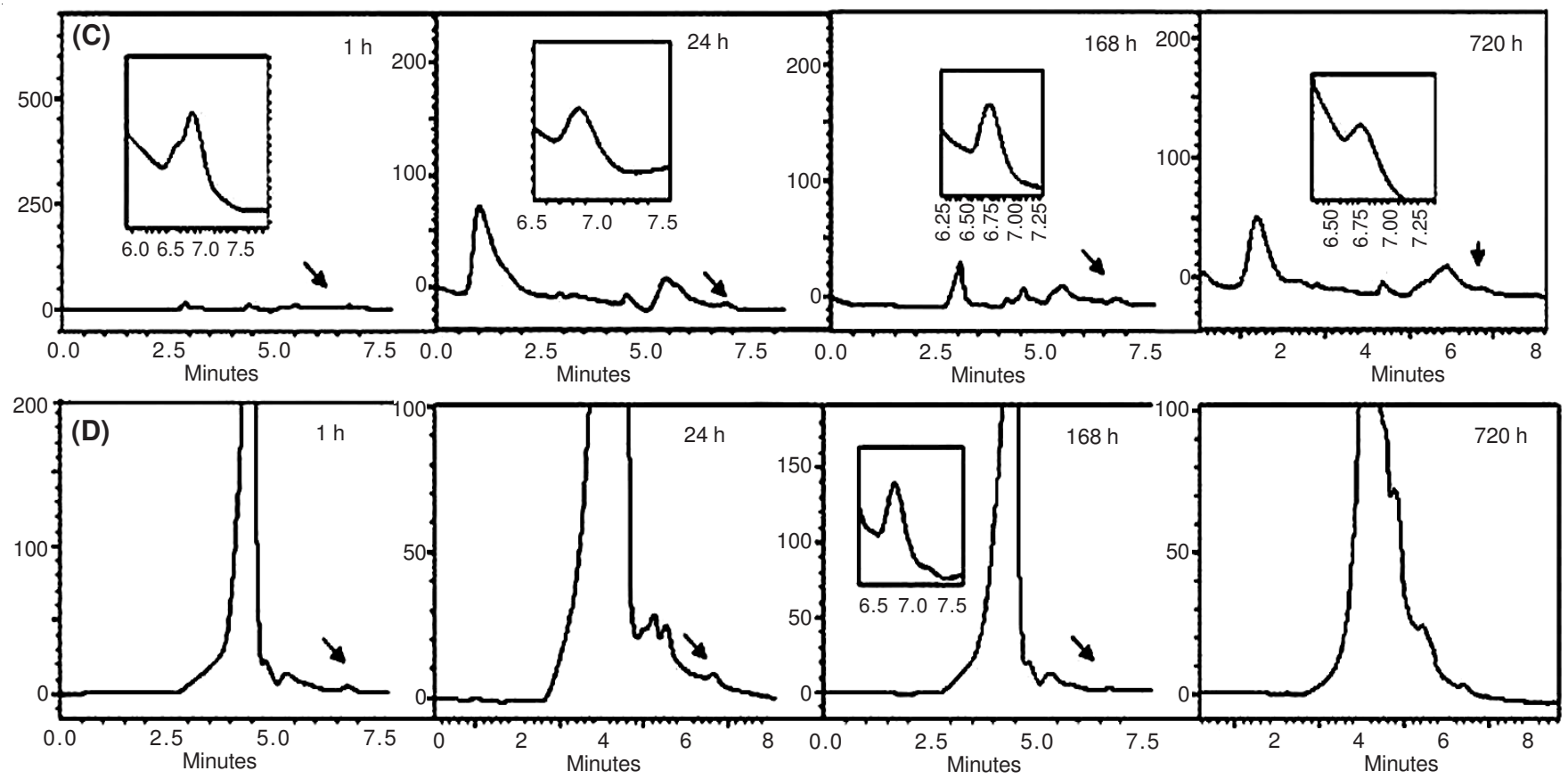

Fig. 1. A) Chromatograms of standard BisGMA between concentration range of 0.2-100 mg/mL in ethanol/water solution (75:25, v/v), distilled water and artificial saliva; B) Chromatograms of BisGMA obtained from dental composite resins (Filtek Z250) for $1 \mathrm{~h}, 24 \mathrm{~h}, 168 \mathrm{~h}(7 \mathrm{~d})$ and $720 \mathrm{~h}(30 \mathrm{~d})$ in ethanol/water solution (75:25, v/v) medium; C) Chromatograms of BisGMA obtained from dental composite resins (Filtek Z250) for 1 h, 24 h, 168 $\mathrm{h}(7 \mathrm{~d})$ and $720 \mathrm{~h} \mathrm{(30} \mathrm{d)} \mathrm{in} \mathrm{distilled} \mathrm{water} \mathrm{medium} \mathrm{;} \mathrm{D)} \mathrm{Chromatograms} \mathrm{of} \mathrm{BisGMA} \mathrm{obtained} \mathrm{from} \mathrm{dental} \mathrm{composite} \mathrm{resins} \mathrm{(Filtek} \mathrm{Z250)} \mathrm{for} 1 \mathrm{~h}, 24$ h, $168 \mathrm{~h} \mathrm{(7} \mathrm{d)} \mathrm{and} 720 \mathrm{~h}(30 \mathrm{~d})$ in artificial saliva medium
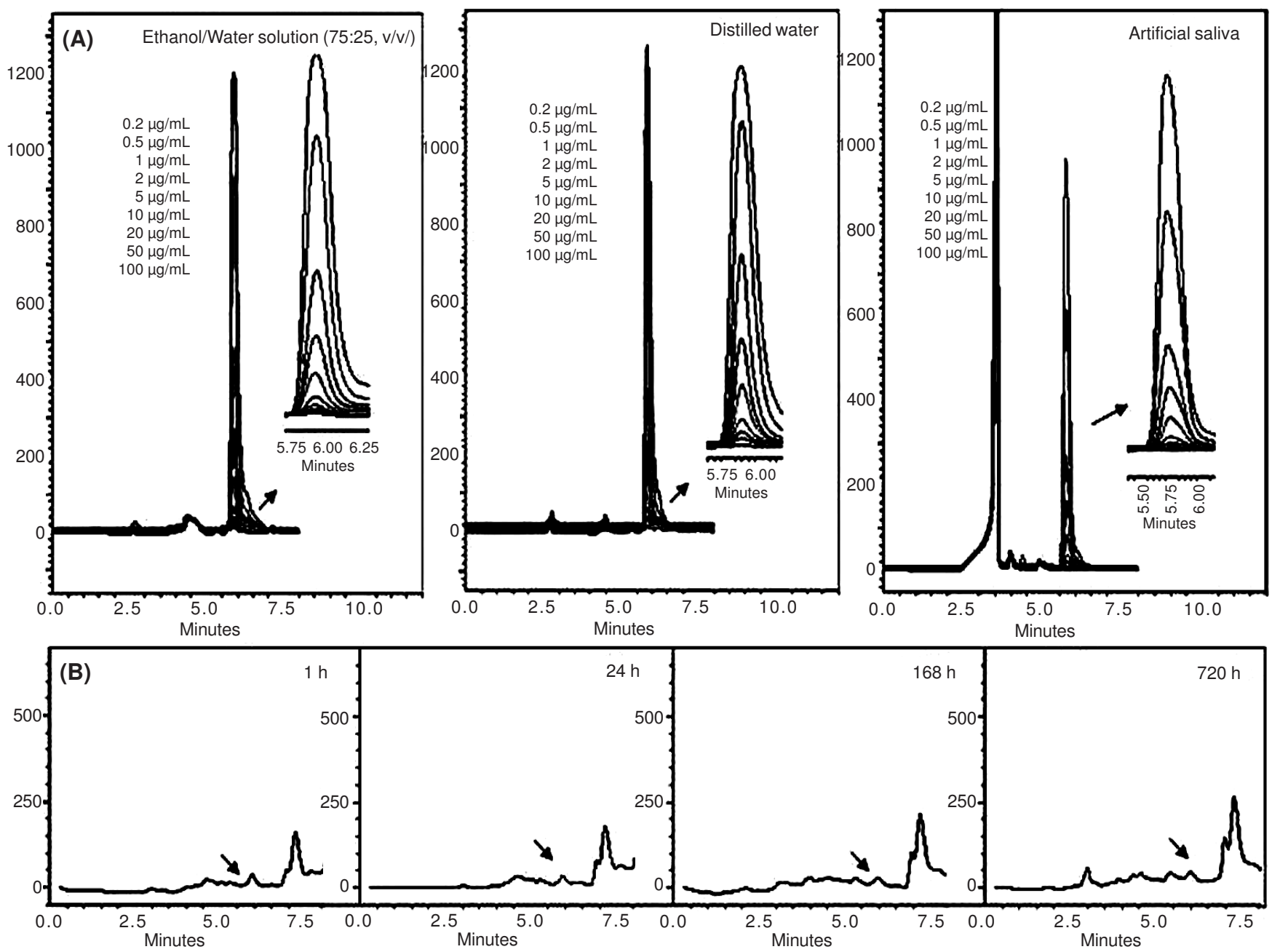

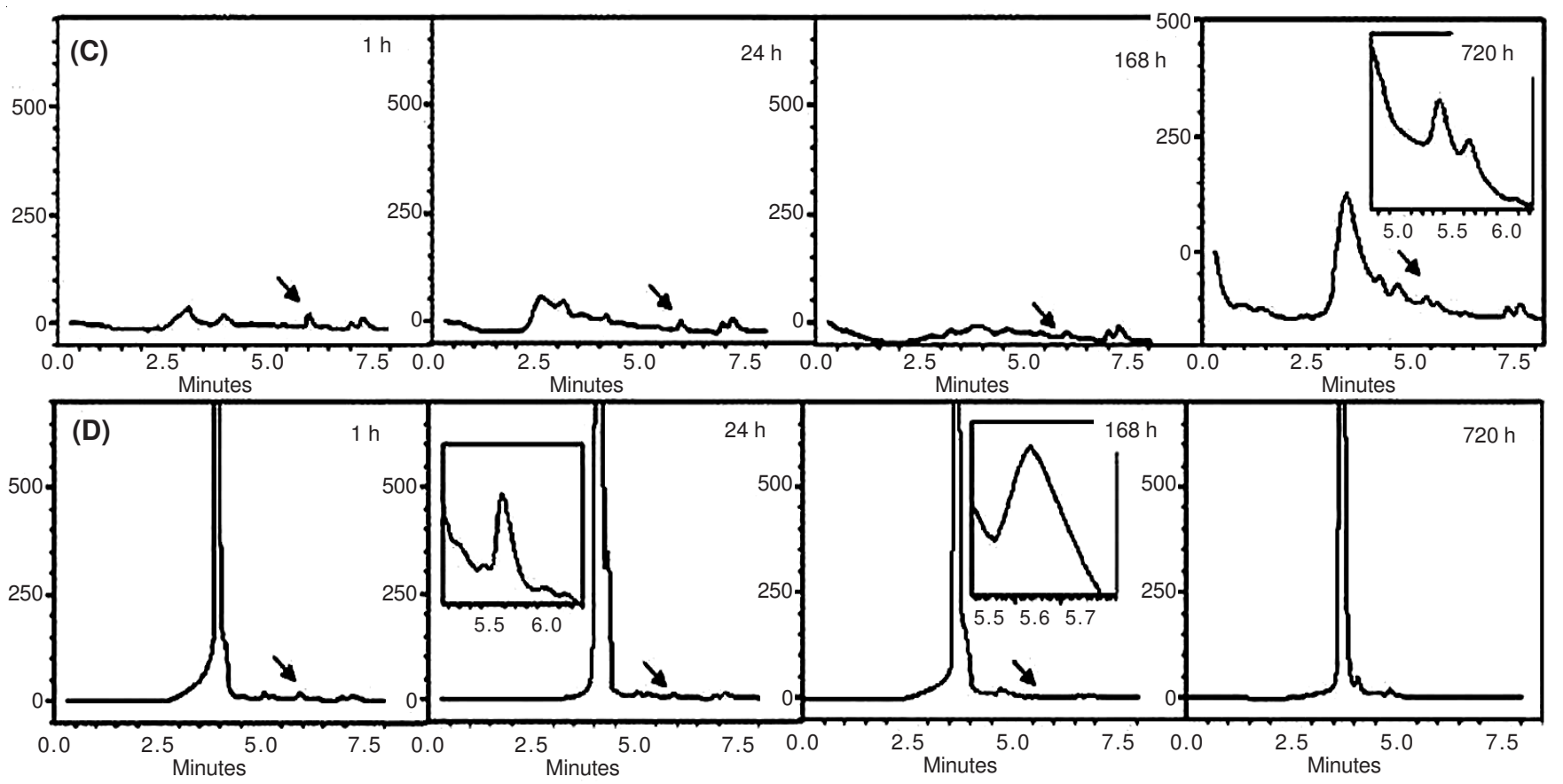

Fig. 2. A) The chromatograms of standard TEGDMA between concentration range of 0.2-100 $\mathrm{mg} / \mathrm{mL}$ in ethanol/water solution (75:25, v/v), distilled water and artificial saliva; B) The chromatograms of TEGDMA obtained from dental composite resins (Filtek Z250) for $1 \mathrm{~h}, 24 \mathrm{~h}, 168 \mathrm{~h} \mathrm{(7} \mathrm{d)} \mathrm{and} 720 \mathrm{~h} \mathrm{(30}$ d) in ethanol/water solution (75:25, v/v) medium; C) The chromatograms of TEGDMA obtained from dental composite resins (Filtek Z250) for 1 h, $24 \mathrm{~h}, 168 \mathrm{~h} \mathrm{(7} \mathrm{d)} \mathrm{and} 720 \mathrm{~h} \mathrm{(30} \mathrm{d)} \mathrm{in} \mathrm{distilled} \mathrm{water} \mathrm{medium;} \mathrm{D)} \mathrm{The} \mathrm{chromatograms} \mathrm{of} \mathrm{TEGDMA} \mathrm{obtained} \mathrm{from} \mathrm{dental} \mathrm{composite} \mathrm{resins} \mathrm{(Filtek}$ $\mathrm{Z} 250)$ for $1 \mathrm{~h}, 24 \mathrm{~h}, 168 \mathrm{~h}(7 \mathrm{~d})$ and $720 \mathrm{~h}(30 \mathrm{~d})$ in artificial saliva medium
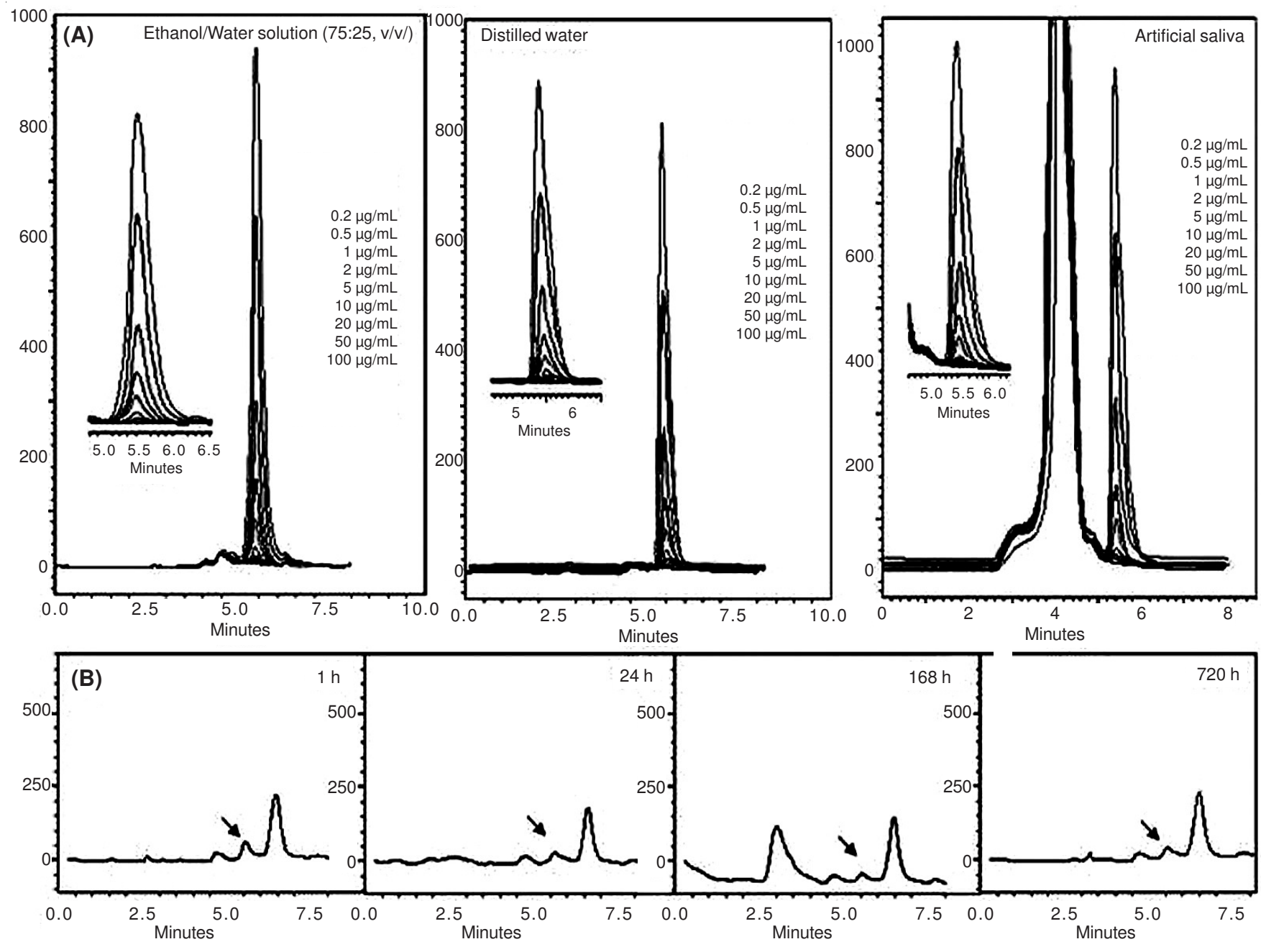

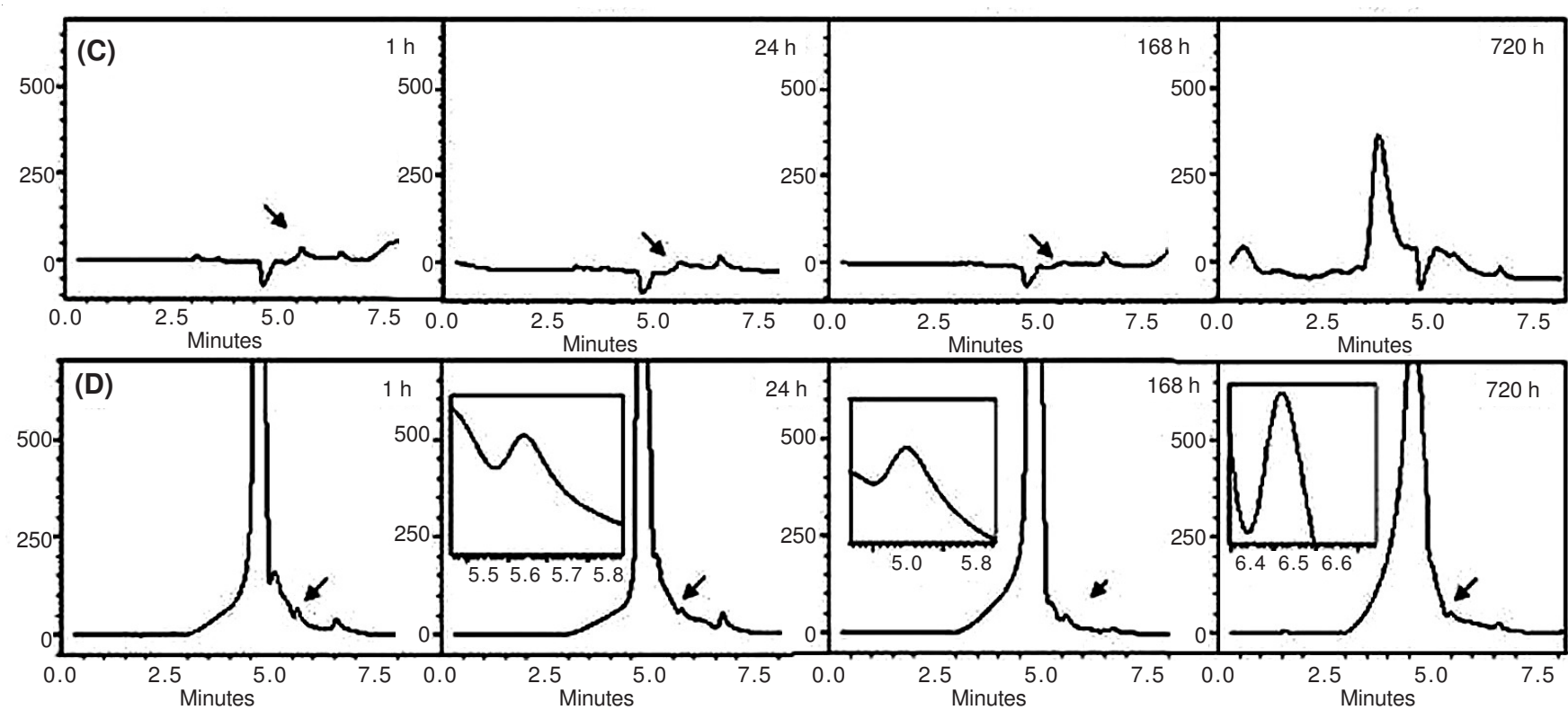

Fig. 3. A) The chromatograms of standard UDMA between concentration range of $0.2-100 \mathrm{mg} / \mathrm{mL}$ in ethanol/water solution (75:25, v/v), distilled water and artificial saliva; B) The chromatograms of UDMA obtained from dental composite resins (Filtek Z250) for $1 \mathrm{~h}, 24 \mathrm{~h}, 168 \mathrm{~h} \mathrm{(7} \mathrm{d)} \mathrm{and} 720 \mathrm{~h}$ (30 d) in ethanol/water solution (75:25, v/v) medium; C) The chromatograms of UDMA obtained from dental composite resins (Filtek Z250) for 1 h, 24 $\mathrm{h}, 168 \mathrm{~h}(7 \mathrm{~d})$ and $720 \mathrm{~h} \mathrm{(30} \mathrm{d)} \mathrm{in} \mathrm{distilled} \mathrm{water} \mathrm{medium;} \mathrm{D)} \mathrm{The} \mathrm{chromatograms} \mathrm{of} \mathrm{UDMA} \mathrm{obtained} \mathrm{from} \mathrm{dental} \mathrm{composite} \mathrm{resins} \mathrm{(Filtek} \mathrm{Z250)} \mathrm{for}$ $1 \mathrm{~h}, 24 \mathrm{~h}, 168 \mathrm{~h}(7 \mathrm{~d})$ and $720 \mathrm{~h}(30 \mathrm{~d})$ in artificial saliva medium

monomer released from samples prepared by using Filtek Z250 composite filling material along certain time periods until from $3 \mathrm{~h}$ to $30 \mathrm{~d}$. As a result, they determined that releasing of monomer occurred reached almost the highest value within $3 \mathrm{~d}$, especially within first $24 \mathrm{~h}$. They also determined that this releasing continued up to $30 \mathrm{~d}$, even not significantly. Polydorou et al..$^{6}$ investigated the amount of monomer released for a long time ( $24 \mathrm{~h}, 7 \mathrm{~d}$ and $28 \mathrm{~d}$ ) after polymerization of the hybrid and flowable composite. Result of their study showed that the maximum releasing occurred within first $24 \mathrm{~h}$ and this releasing continued along $28 \mathrm{~d}$. In this study, maximum release of all monomers occured within the first hour $(\mathrm{p}<$ 0.05 ) after $24 \mathrm{~h}$, the amount of released monomer generally reduced by $30 \mathrm{~d}$.

The findings from studies mentioned above are different from each other in terms of monomer rates released from composite materials and their releasing times.

Several factors contribute to the process of elution from resin-based dental materials. According to Ferracane ${ }^{27}$ released monomer amount is first affected by the polymerization reaction (i.e. the degree of double bond conversion). Second, the chemical properties of the solvent have a significant effect on the elution. Third, the size and the chemical nature of the released components play a role.

In various studies it has been found that the degree of the monomer-polymer conversion of dental resin composites varies between approximately $35 \%$ and $77 \%$ 3,27,28. Tanaka et al. ${ }^{7}$ found that increasing the irradiation time from $30 \mathrm{~s}$ to $50 \mathrm{~s}$ resulted in a significant decrease in residual monomer contents and the quantities which were released into water. In contrast to this study, Ferracane ${ }^{27}$ found a poor correlation between the elution and the degree of conversion for composites aged in water for $48 \mathrm{~h}$ whereas the correlation for ethanol/ water much better.
Several studies have been performed to determine the influence of the type of solvent upon the release of substances from resin composites. An ethanol/water solution is considered the best solvent for dental composite resins ${ }^{27,29}$. Ferracane ${ }^{27}$ stated that the intraoral fluids represent solvents probably somewhere between the more aggressive organic solvents and water, which is less effective than pure ethanol. Ferracane and Condon ${ }^{28}$ compared the rate of elution from a microfilled composite using water and a ethanol/water mixture. They found that $50 \%$ of the leachable components were extracted by water within $3 \mathrm{~h}$, but in the ethanol/water mixture within $24 \mathrm{~h}$, nearly all leachable substances (unbound monomers and oligomers) were eluted.

Similar to these studies, at present study, it was determined that amount of residual monomer in by the ethanol/water mixture was significantly higher than distilled water and artificial saliva. This difference can be attributed to the greater ability of the organic solvent to penetrate and swell the polymer network, facilitating the liberation of residual monomers and promoting a stronger degradative effect ${ }^{5,27}$.

An important factor affecting residual monomer leaching is the nature and the size of the monomers in the resin materials. Ortengren et al. ${ }^{20}$ stated that smaller molecules are expected to leach more and more rapid than larger, bulkier molecules. Therefore it was presumed that TEGDMA would leach better than BisGMA. In contrast to these findings, Komurcuoglu et $a l .{ }^{30}$ determined that BisGMA released from resin materials was higher than TEGDMA. According to them, these results might be caused by differences in chemical properties and reactive potentials of BisGMA and TEGDMA, as double bond conversion of BisGMA is lower than TEGDMA. Additionally, another reason can be the solution that was used for the storage of the samples. An ethanol/water solution has the solubility parameter which matches that of BisGMA ${ }^{6}$. 
In this study, it was determined that the released amount of TEGDMA in distilled water and artificial saliva is higher than BisGMA, but the case is reverse in ethanol/water solution. According this finding, it may be suggested that the most effective factor for releasing monomer is extraction medium because the releasing of monomer changes by changing media. It may be also suggested that ethanol/water solution (75:25, $\mathrm{v} / \mathrm{v}$ ) is the most effective extraction medium.

\section{Conclusion}

The results of this study showed that:

1. Effect on the amount of released monomers from dental composites depend on the immersion media where ethanol/ water solution $(75: 25, \mathrm{v} / \mathrm{v})$ had the most significant effect in terms of released monomer amount.

2. Maximum release of all monomers occured within the first hour.

3. For minimizing, the extractable quantities of residual monomers from composites, less water soluble and polymerizable monomers should be used.

4. To protect the patient from potential hazards of residual monomers is very important, therefore all components of dental composites should be declared by the manufacturer.

\section{ACKNOWLEDGEMENTS}

This study was presented in poster format at the XV. Departments of Restorative Dentistry Meeting in Trabzon, Turkey (2010). The authors thank Prof. H. Murat Akgül for helping in statistical analysis.

\section{REFERENCES}

1. O. Polydorou, A. Konig, E. Hellwig and K. Kummerer, Eur. J. Oral Sci., 117, 68 (2009).

2. I.D. Sideridou and D.S. Achilias, J. Biomed. Mater. Res. Part B: Appl. Biomater, 74B, 617 (2005).

3. W. Geurtsen, Eur. J. Oral Sci., 106, 687 (1998).

4. H. Oysaed and I.E. Ruyter, J. Biomed. Mater. Res., 20, 261 (1986).
5. L.R.P. Archegas, R.N. Rached, S.A. Ignacio, E.C. Vasconcelos, D.T. Ramos and E.M. Souza, Braz. Arch. Biol. Technol., 52, 855 (2009).

6. O. Polydorou, R. Trittler, E. Hellwig and K. Kummerer, Dent. Mater., 23, 1535 (2007).

7. K. Tanaka, M. Taira, H. Shintani, K. Wakasa and M. Yamaki, J. Oral Rehabil., 18, 353 (1991).

8. K. Moharamzadeh, R.V. Noort, I.M. Brook and A.M. Scutt, J. Mater. Sci.: Mater. Med., 18, 133 (2007).

9. M. Toledano, R. Osorio, E. Osorio, F.S. Aguilera, A. Romeo, B. Higuera and F. Garcia-Godoy, J. Biomed. Mater. Res., 76B, 251 (2006).

10. I.D. Sideridou, D.S. Achilias and M.M. Karabela, J. Biomed. Mater. Res. Part B: Appl. Biomater, 81B, 207 (2007).

11. Y. Zhang and J. Xu, J. Mater. Sci: Mater. Med., 19, 2477 (2008)

12. E.C. Munksgaard, A. Peutzfeldt and E. Asmussen, Eur. J. Oral Sci., 108, 341 (2000).

13. M. Noda, H. Komatsu and H. Sano, J. Biomed. Mater. Res., 47, 374 (1999).

14. H.J. Moon, B.S. Lim, Y.K. Lee and C.W. Kim, Bull. Korean. Chem. Soc., 21, 1115 (2000).

15. Y.H. Bagis and F.A. Rueggeberg, Dent. Mater, 16, 244 (2000).

16. V.M. Vaubert, P.C. Moon and B.J. Love, J. Biomed. Mater. Res: Appl. Biomater, 48, 5 (1999).

17. P. Dolez, M. Mare and B.J. Love, J. Appl. Polym. Sci., 82, 546 (2001).

18. A. Hamid and W.R. Hume, Dent. Mater., 13, 98 (1997).

19. H. Tarumi, S. Imazato, A. Ehara, S. Kato, N. Ebi and S. Ebisu, Dent. Mater., 15, 238 (1999).

20. U. Ortengren, H. Wellendorf, S. Karlsson and I.E. Ruyter, J. Oral Rehabil., 28, 1106 (2001).

21. R. Pulgar, M.F. Olea-Serrano, A. Novillo-Fertrell, A. Rivas, P. Pazos, V. Pedraza, J.M. Navajas and N. Olea, Environ. Health Perspect., 108, 21 (2000).

22. N.A. Chowdhury, K. Wakasa, R. Priyawan and M. Yamaki, J. Mater. Sci. Lett., 15, 1912 (1996).

23. S.Y. Lee, H.M. Huang, C.Y. Lin and Y.H. Shih, J. Oral Rehabil., 25, 575 (1998)

24. V.B. Michelsen, H. Lygre, R. Skalevik, A.B. Tveit and E. Solheim, Eur. J. Oral Sci., 111, 263 (2003).

25. W. Spahl, H. Budzikiewicz and W. Geurtsen, J. Dent., 26, 137 (1998).

26. S.A. Mazzaoui, M.F. Burrow, M.J. Tyas, F.R. Roney and R.J. Capon, J. Biomed. Mater. Res: Appl. Biomater, 63, 299 (2002).

27. J.L. Ferracane, J. Oral Rehabil., 21, 441 (1994).

28. J.L. Ferracane and J.R. Condon, Dent. Mater, 6, 282 (1990).

29. M.H. Tabatabaee, H. Mahdavi, S. Zandi and M.J. Kharrazi, J. Biomed. Mater. Res. Part B: Appl. Biomater, 88B, 191 (2009).

30. E. Komurcuoglu, S. Olmez and N. Vural, J. Oral Rehabil., 32, 116 (2005). 